\title{
Executive Functions and Thyroid Volumes in Bipolar Patients on Lithium Treatment
}

\author{
Nurhan Fistikci ${ }^{1}$, GulsumCanturk ${ }^{1}$, Omer Saatcioglu ${ }^{2}$, EvrimErten ${ }^{1}$, Ali Keyvan $^{1}$ and Nurten Turan ${ }^{3}$ \\ ${ }^{1}$ Bakirkoy Research and Training Hospital for Psychiatry, Neurology and Neurosurgery, Istanbul,Turkey \\ 2/sik University, Department of Psychology, Istanbul, Turkey \\ ${ }^{3}$ Bakirkoy Sadi Konuk Research and Training Hospital, Istanbul, Turkey
}

*Corresponding author: Nurhan Fıstıkcı, Bakırköy Ruh Ve Sinir Hastalıkları Hastanesi. Bakırköy 34147, Istanbul Turkey; Tel: 905335261366; E-mail: nurhanfistikci@gmail.com

Received Date: June 6, 2014, Accepted Date: September 23, 2014, Published Date: September 30, 2014

Copyright: (c) 2014, Nurhan Fistikci et al., This is an open-access article distributed under the terms of the Creative Commons Attribution License, which permits unrestricted use, distribution, and reproduction in any medium, provided the original author and source are credited.

\begin{abstract}
Aim: The purpose of this study was to investigate the relationship between executive functions and thyroid ultrasound parameters in remitted bipolar patients who were on lithium treatment. Methods: In the current study, 25 remitted patients with diagnoses of Bipolar I Disorder having blood lithium, and thyroid hormone levels within the normal range were consecutively enrolled. Healthy control group consisted of 25 euthyroid people matched as an age, sex and education level with the patients. Semi-structured sociodemographic and clinical form, the Structured Clinical Interview for DSM-IV Axis I Disorders, the Montreal Cognitive Assessment (MoCA), the Hamilton Depression Scale, Young Mania Rating Scale, thyroid ultrasonography and the Wisconsin Card Sorting Test (WCST) were applied to both groups. Within the patient group, correlation analysis was performed between WCST performance and thyroid volume. Results: In the present study, no significant difference was found between the bipolar and the healthy control groups regarding the executive functions as measured via WCST. In the bipolar patients, there were no statistically significant correlations among WCST scores and thyroid volumes. Conclusion: Thyroid volumes are not appeared to be associated with executive functions in euthymic bipolar patients.
\end{abstract}

Keywords: Bipolar disorder; WCST; Thyroid Ultrasonography; Executive function

\section{Introduction}

It is known that the most frequent affects of lithium on the thyroid are hypothyroidism and goiter [1]. The most commonly observed cognitive impairments associated with hypothyroidism include amnesia, attention deficit, slowed processing speed and depressed mood [2]. Executive functions concerns with the higher-level cognitive skills. Additionally, high TSH values can cause a reduction in cognitive functions [3].

Although cognitive impairment is well-defined in clinical hypothyroidism [4], there are some conflicting reports on cognitive changes in subclinical hypothyroidism [5,6]. Benign non-toxic diffuse goiter has been reported in individuals using lithium for long periods, with rates ranging between 3.8 and $51 \%$ [7-14]. It is important to answer the question whether TSH-suppression treatment should be initiated immediately after the diagnosis of goiter in patients treated with lithium [15]. Monitoring changes in thyroid volumes with thyroid ultrasonography is recommended when goiter is diagnosed in lithium therapy [16-18]. Studies have indicated that lithium treatment is a risk factor for increased thyroid volume in patients with bipolar disorder, and these patients may be monitored with thyroid ultrasonography at the baseline and follow-up [5,19-23]. Even though hypothyroidism is associated with cognitive dysfunctions in the literature, the effects of thyroid volume enlargement without hormonal changes are not comprehensively investigated.

It is known that lithium may cause hypothyroidism and that executive functions are also affected in patients developing hypothyroidism. Subclinical hypothyroidism has been psychiatrically investigated, and studies have been conducted investigating its relationship with executive functions. However, the effects of the changes in thyroid parameters measured by thyroid ultrasonography before these changes in hormone levels have occurred are not clear. In the current study, we hypothesized those ultra-sound measurements of thyroid gland volumes correlate with WCST scores in bipolar disorder type I.

\section{Method}

\section{Participants}

Twenty-five patients with DSM-IV diagnoses of Bipolar I Disorder who were receiving treatment and follow-up therapy in outpatient settings were consecutively included in this study. The control group consisted of 25 subjects who were eligible based on study criteria. Patients with bipolar disorder who were euthymic (YMRS score of $<5$, HAM-D score of $<7$ ) for at least 8 weeks and who had at least two blood lithium levels measured within the last 6 months at normal limits (0.6-1.2 meq/l) were included in the study. Five out of 30 subjects in the patient group and 6 out of 31 subjects in the control group were excluded from study due to detection of nodules in thyroid USG imaging. Written consents of the patient and control groups and ethical committee approval for the study were obtained.

Patients were included if they had been in remission for at least two months and had free thyroxine (fT4), free triiodothyronine (fT3), and Thyroid-stimulating hormone (TSH) values at normal limits (TSH: 0.35-4.94 uI U/ml; fT3: 1.71-3.71 pgr/mL; fT4: 0.70-1.48 ng/dL). Exclusion criteria for the study included education and language 
Page 2 of 6

problems preventing administration of the diagnostic psychiatric interview, scores of $<21$ in the MoCA test, diagnosis of any degenerative neurological disorder, dementia, mental retardation, epilepsy, cerebral tumors or cerebrovascular disease, history of head trauma causing loss of consciousness, endocrine disease, any concurrent axis I psychiatric diagnosis, diagnosis of alcohol or substance dependence within the last year, contraindications against the ultrasonography procedure (e.g., a significant wound scar or tissue defect on the neck that deteriorated or limited the extension and acoustic permeability of neck), pregnancy, electroconvulsive therapy (ECT) within last 6 months, fT4, fT3, or TSH values outside of normal limits and nodules, masses or abnormal vascularization in thyroid ultrasonography. Subjects in the control group were between 18 and 65 years, had fT4, fT3, and TSH values at normal limits and met inclusion using similar evaluation criteria to those applied to the patient group.

Thyroid function tests measuring fT4, fT3, and TSH levels were administered at the same laboratory for both patients and control group subjects. Axis I or any other diagnosis was determined using the SCID-I, which was established for patients and healthy controls. Groups were compared with respect to their WCST performances. The correlation between WCST performance and thyroid volumes of the patient group was investigated.

\section{Measurements}

\section{Socio-demographic and clinical characteristics data form}

Variables such as gender, age, marital status, education, work status, income status, age at onset of bipolar disorder, drug use, and history of familial psychiatric disease were incorporated in a semi-structured form developed by investigators to include socio-demographic and clinical characteristics.

\section{Wisconsin Card Sorting Test (WCST)}

The WCST is test for assessing executive functions [24]. The test evaluates decision-making and flexibility, responsiveness to feedback and problem-solving skills of an individual [25]. A computerized form of the test was used in this study. A key card and four response cards, which are similar to key card but have differences in color, geometric shape and number, appear on the screen. Participants are told to match each response card with the key cards. After each match, feedback ("right" or "wrong") is given. Following 10 consecutive correct answers, the desired matching principle is changed without warning. The participant is told to match the cards according to the change made. There are no time limitations placed on the test; it continues until the completion of six categories or 64 attempts.

\section{Montreal Cognitive Assessment (MoCA)}

The MoCA was developed as a quick scan test for mild cognitive impairment by assessing different cognitive functions. These functions include attention and concentration, executive functions, memory, language, visual constitution skills, abstract thinking, calculation and orientation. The maximum score of the test is 30 .

Accordingly, scores of $\geq 21$ are considered within normal limits [26].

\section{Hamilton Depression Rating Scale (HAM-D)}

This scale was developed by Hamilton toassess severity of depressive symptoms in patients diagnosed with depression and is administered by an interviewer. A Turkish validity and reliability study was conducted by Akdemiret al. [27].

\section{Young Mania Rating Scale}

This scale was developed by Young et al. in 1978 to measure these verities in and change of manic state and is administered by an interviewer. It is composed of a total of 11 items. A Turkish validity and reliability study was conducted by Karadag et al. [28].

\section{SCID-I}

This structured interview was developed to facilitate DSM-IV Axis I diagnosis [29]. A Turkish reliability and validity study was conducted by Çorapçıŏlu et al. [30].

\section{SCID-I/NP}

This semi-structured clinical interview tool was developed to exclude DSM-III-R diagnoses 31. The Turkish adaptation was conducted by Sorias et al. [32].

\section{Thyroid Ultrasonography}

Thyroid sonographies were performed by the same radiologistusing a VFX 9-4 multi-D matrix probe ultrasonography device by Siemens Acuson Antares (Siemens, USA). The central frequency was adjusted to $7 \mathrm{mHz}$, with the probe having a frequency range of 4 to $9 \mathrm{mHz}$, and the transverse and anteroposterior lengths on the axial plane and the craniocaudal length on the sagittal plane were measured for both thyroid lobes using an electronic ruler.

\section{Statistical analysis}

Statistical analyses for the study were performed with the SPSS 14.00 program. In statistical evaluations of study data, chi-square tests were used to assess the relationships between definitive methods (i.e., frequency, median, and standard deviation) and categorical variables. Chi-square tests and Mann-Whitney $U$ tests were used to compare non-parametric values. Spearman correlation analysis was applied to determine relationships between the variables. The significance level was established as $\mathrm{p}<0.05$.

\section{Results}

\section{Socio-demographic characteristics}

No differences were found between the patient group and the control group with respect to gender, age or education $(p>0.05)$. Mean age was $34.68 \pm 7.83$ years for the patient group and $33.00 \pm 5.45$ for the control group. There were 11 female (44\%) and 14 male patients (56\%) in the patient group and 11 female (44\%) and 14 male patients (56\%) in control group. Duration of education was $11.48 \pm 4.18$ years for the patient group and $12.20 \pm 4.12$ for the control group.

\section{Clinical characteristics}

All patients were receiving treatment and follow-up therapy for the diagnosis of Bipolar I Disorder, and their average disease duration was $11.00 \pm 6.73$ years. The mean age at onset of the disease was $23.68 \pm$ 
Page 3 of 6

9.25 years. All patients were using lithium, and the mean duration of lithium use was $77.00 \pm 59.49$ months. The mean number of episodes was $4.72 \pm 2.38$, the mean number of manic episodes was $2.76 \pm 1.36$, the mean number of depressive episodes was $1.96 \pm 1.76$ and the mean number of mixed episodes was $0.04 \pm 0.20$. When evaluated for psychotic features, the mean number of manic episodes with psychotic features was $1.28 \pm 1.10$, the mean number of depressive episodes with psychotic features was $0.76 \pm 1.20$ and the mean number of mixed episodes with psychotic features was $0.04 \pm 0.20$. The mean number of hospitalizations for those in the patient group was $1.40 \pm 1.11$.

Of the first-degree relatives of the patients, 8 individuals had bipolar disorder (32\%), 2 individuals had schizophrenia (8\%), 3 individuals had an anxiety disorder or a depressive disorder (12\%) and 12 individuals $(48 \%)$ had no psychiatric history. None of the patients used drugs. Thirteen (52\%) of the patients were smokers. Five (20\%) patients had a history of alcohol use; however, they did not meet dependency or abuse criteria. One (4\%) patient had one suicide attempt and 1 (4\%) patient had two suicide attempts. Twenty-three (92\%) patients had no history of suicide attempt. Only one patient had hypertension as a medical disease, and 7 (28\%) patients had a family history of alcohol or drug use. The periods of longest remission among patients were 6-12 months for 3 patients (12\%), 12-24 months for 4 patients (16\%) and $\geq 24$ months for 18 patients (72\%).

Eight patients (32\%) were using lithium alone, 15 patients $(60 \%)$ were using a lithium + antipsychotic combination, and 2 patients (8\%) were using a lithium + antipsychotic + antidepressant combination.

\section{Comparison of Thyroid Measurements}

USG parenchymal echo patterns in patient group were found to be homogeneous in 21 subjects (84\%), minimally heterogeneous in 1 subject (4\%) and remarkably heterogeneous in 3 subjects (12\%). USG parenchymal echo patterns in the control group were found to be homogeneous in 23 subjects (92\%) and minimally heterogeneous in 2 subjects (8\%). When patient and control groups were compared across thyroid measurements, statistically significant differences were found in all measurements except for the thyroid USG right lobe sagittal diameter $(\mathrm{z}=1.50, \mathrm{p}=0.13)$ and the thyroid USG left lobe sagittal diameter $(\mathrm{z}=0.77 ; \mathrm{p}=0.43)$. Thyroid diameters were larger in bipolar patients (Table 1).

\section{Neuropsychological Assessment:}

The mean MoCA score was $26.44 \pm 2.43$ in the patient group and $27.32 \pm 2.21$ in the control group. A significant difference $(z=-1.60$, $\mathrm{p}=0.10$ ) was not found when the average MoCA test scores for both of the groups were compared. Although the patient group had lower Performance in all sub-parameters of the WCST test compared to healthy controls, no statistically significant difference was found between two groups ( $\mathrm{p}>0.05$ ) (Table 2).

\section{Comparison of Thyroid USG Measurements and WCST Results of Patient and Control Groups}

All correlations among WCST scores and thyroid volume measurements were considered to be statistically insignificant $(\mathrm{p}>0.05)$ (Table 3).

\section{Discussion}

In the current study, although the euthymic patients with bipolar disorder using lithium had lower performance in all subcategories of WCST test, no statistically significant differences were found between the patient and control groups. Furthermore, no significant correlations between measures of perseveration on the WCST and thyroid volumes were found in bipolar patients. Complex (executive) attention, determination of features, perseveration, working memory, executive functioning, conceptualization and abstract thinking are measured by the WCST [33-35].

\begin{tabular}{|c|c|c|c|c|c|}
\hline & Sample & Mean & SD & $z$ & $p$ \\
\hline \multirow[t]{2}{*}{$\begin{array}{l}\text { Thyroid USG Mean Right } \\
\text { Lobe Volume }\end{array}$} & Patient & 9709.58 & 3897.70 & 4.16 & $\begin{array}{c}<0.00 \\
1^{*}\end{array}$ \\
\hline & Control & 6045.35 & 2039.53 & & \\
\hline \multirow[t]{2}{*}{$\begin{array}{c}\text { Thyroid USG Mean Left Lobe } \\
\text { Volume }\end{array}$} & Patient & 7964.73 & 3303.04 & 3.53 & 0.001 \\
\hline & Control & 5240.21 & 1976.76 & & \\
\hline \multirow[t]{3}{*}{ Thyroid USG Mean Volume } & Patient & 8831.17 & 3473.80 & 4.03 & $<0.00$ \\
\hline & Control & 5640.78 & 1888.43 & & \\
\hline & Control & 13.72 & 2.22 & & \\
\hline
\end{tabular}

Table 1: Comparisons of thyroid USG measurements between the patient and control groups

Perseveration is the main abnormality in WCST and it was not found to be associated with thyroid volume in euthymic bipolar patients using lithium. In light of this information, one can think that increased thyroid volumes do not signify a failure in executive functions as measured via WCST performance in euthymic bipolar patients using lithium. However, this should be confirmed in larger samples. When the patient and control groups were compared across thyroid measurements, statistically significant differences were found in all thyroid measurements, with thyroid volumes being greater among bipolar patients except in the cases of the thyroid USG right lobe sagittal diameter and the thyroid USG left lobe sagittal diameter. Other conditions exist that require the use of imaging in addition to biochemical and immunological methods in monitoring possible changes in the thyroid gland; the use of thyroid ultrasonography is recommended, for example, for following up on the changes occurring in thyroid volume when goiter is diagnosed [20]. In a study conducted by Özsoy et al. that compared bipolar patients using or not using lithium with healthy controls, findings similar to ours were reported: namely, that increases in volume and thyroid hormone changes measured by ultrasonography were greater in the group not using lithium compared to the healthy controls and in the patient group using lithium compared to the patient group not using lithium.

Moreover, they recommended the use of thyroid ultrasonography prior to initiation of and during follow-up of lithium therapy [23]. Considering the affects of lithium on the thyroid, early diagnosis may be ensured by ultrasonographic monitoring, a non-invasive examination, in cases undetectable by palpation. In other studies, benign non-toxic diffuse goiter has been reported in cases using lithium for long periods, with prevalence rates ranging between 3.8 and $51 \%[6,8-13]$. 
Citation: Fistikci N, Canturk G, Saatcioglu O, Erten E, Keyvan A, et al. (2014) Executive Functions and Thyroid Volumes in Bipolar Patients on

\begin{tabular}{|c|c|c|c|c|c|}
\hline WCST Scores & Sample & Mean & SD & $\mathbf{z}$ & p \\
\hline \multirow[t]{2}{*}{ Mean Score for Total Number of Correct Answers } & Patient & 37.88 & 9.61 & -1.26 & 0.20 \\
\hline & Control & 40.72 & 14.26 & & \\
\hline \multirow[t]{2}{*}{ Mean Score for Total Number of Wrong Answers } & Patient & 26.12 & 9.61 & 1.30 & 0.14 \\
\hline & Control & 22.08 & 12.14 & & \\
\hline \multirow[t]{2}{*}{ Mean Score for Total Number of Perseverative } & Patient & 16.48 & 7.78 & 1.00 & 0.31 \\
\hline & Control & 14.04 & 9.24 & & \\
\hline \multicolumn{6}{|l|}{ Responses } \\
\hline \multirow[t]{2}{*}{$\begin{array}{l}\text { Mean Score for Total Number of Non- } \\
\text { Preservatives Errors }\end{array}$} & Patient & 11.80 & 5.89 & 1.13 & 0.26 \\
\hline & Control & 9.88 & 6.02 & & \\
\hline \multirow[t]{2}{*}{$\begin{array}{l}\text { Mean Score for Total Number of Preservatives } \\
\text { errors }\end{array}$} & Patient & 14.32 & 5.94 & 1.09 & 0.27 \\
\hline & Control & 12.20 & 7.58 & & \\
\hline \multirow[t]{2}{*}{ Mean Score for Number of Completed Categories } & Patient & 1.96 & 1.20 & -1.09 & 0.27 \\
\hline & Control & 2.44 & 1.82 & & \\
\hline \multirow[t]{2}{*}{ Mean Score for Percentage of Preservative errors } & Patient & 22.36 & 9.29 & 1.10 & 0.27 \\
\hline & Control & 19.02 & 18.5 & & \\
\hline \multirow[t]{2}{*}{$\begin{array}{l}\text { Mean Score for Number of Responses Used to } \\
\text { Complete the First Category }\end{array}$} & Patient & 21.00 & 13.02 & 1.74 & 0.08 \\
\hline & Control & 15.19 & 8.22 & & \\
\hline \multirow[t]{2}{*}{$\begin{array}{l}\text { Mean Score for Percentage of Conceptual Level } \\
\text { Responses }\end{array}$} & Patient & 46.98 & 23.16 & -1.25 & 0.21 \\
\hline & Control & 56.06 & 27.65 & & \\
\hline \multirow[t]{2}{*}{ Mean Score for Failure to Maintain Set } & Patient & 0.80 & 1.15 & 0.41 & 0.67 \\
\hline & Control & 0.68 & 0.85 & & \\
\hline
\end{tabular}

Table 2: Comparisons of WCST test results between the patient and control groups

\begin{tabular}{|l|l|l|l|l|l|l|l|l|l|l|}
\hline & WCST 1 & WCST 2 & WCST 3 & WCST 4 & WCST 5 & WCST 6 & WCST 7 & WCST 8 & WCST 9 & WCST10 \\
\hline Thyroid Mean & $\mathrm{r}=-0.14$ & $\mathrm{r}=0.14$ & $\mathrm{r}=0.09$ & $\mathrm{r}=0.28$ & $\mathrm{r}=0.11$ & $\mathrm{r}=-0.16$ & $\mathrm{r}=0.11$ & $\mathrm{r}=-0.01$ & $\mathrm{r}=-0.16$ & $\mathrm{r}=-0.19$ \\
\hline Right Lobe Volume & $\mathrm{p}=0.50$ & $\mathrm{p}=0.50$ & $\mathrm{p}=0.64$ & $\mathrm{p}=0.17$ & $\mathrm{p}=0.59$ & $\mathrm{p}=0.43$ & $\mathrm{p}=0.59$ & $\mathrm{p}=0.95$ & $\mathrm{p}=0.43$ & $\mathrm{p}=0.36$ \\
\hline Thyroid Mean & $\mathrm{r}=-0.08$ & $\mathrm{r}=0.08$ & $\mathrm{r}=0.06$ & $\mathrm{r}=0.19$ & $\mathrm{r}=0.05$ & $\mathrm{r}=-0.28$ & $\mathrm{r}=0.05$ & $\mathrm{r}=0.05$ & $\mathrm{r}=-0.10$ & $\mathrm{r}=0.02$ \\
\hline Left Lobe volume & $\mathrm{p}=0.67$ & $\mathrm{p}=0.67$ & $\mathrm{p}=0.74$ & $\mathrm{p}=0.35$ & $\mathrm{p}=0.78$ & $\mathrm{p}=0.17$ & $\mathrm{p}=0.78$ & $\mathrm{p}=0.81$ & $\mathrm{p}=0.61$ & $\mathrm{p}=0.91$ \\
\hline Thyroid Mean & $\mathrm{r}=-0.15$ & $\mathrm{r}=0.15$ & $\mathrm{r}=0.10$ & $\mathrm{r}=0.26$ & $\mathrm{r}=0.12$ & $\mathrm{r}=-0.27$ & $\mathrm{r}=0.12$ & $\mathrm{r}=0.00$ & $\mathrm{r}=-0.16$ & $\mathrm{r}=-0.09$ \\
\hline Volume & $\mathrm{p}=0.46$ & $\mathrm{p}=0.46$ & $\mathrm{p}=0.60$ & $\mathrm{p}=0.19$ & $\mathrm{p}=0.55$ & $\mathrm{p}=0.19$ & $\mathrm{p}=0.55$ & $\mathrm{p}=0.99$ & $\mathrm{p}=0.42$ & $\mathrm{p}=0.65$ \\
\hline
\end{tabular}

Table 3: Comparisons of thyroid USG measurements and WCST results in the patient group

WCST 1: Mean Score for Total Number of Correct Answers, WCST 2: Mean Score for Total Number of Wrong Answers, WCST 3: Mean Score for Total Number of Preservatives Responses, WCST 4: Mean Score for Total Number of Non-Preservatives Errors, WCST 5: Mean
Score for Total Number of Preservatives Errors, WCST 6: Mean Score for Number of Completed Categories, WCST 7: Mean Score for Percentage of Preservatives Errors, WCST 8: Mean Score for Number of Responses Used to Complete the First Category, WCST 9: Mean 
Score for Percentage of Conceptual Level Responses, WCST 10: Mean Score for Failure to Maintain Set

$$
{ }^{*}=\text { Statistically significant, } \mathrm{r}=\text { Spearman's test }
$$

Thyroid function is within normal levels in most patients developing goiter. Therefore, it is very important to identify and treat at early stages any hypothyroidism that may develop due to lithium administration. Our findings, consistent with the literature, showed that thyroid volume is increased in patients with bipolar disorder using lithium.

Because the patient group was composed mainly of patients who were regularly monitored at a mood disorder clinic, remitted for a long time, identified as regular drug users, and administered lithium alone for regulation of their mood disorder, the ability to generalize these findings to a larger population of bipolar patients is limited. Another limitation of the study was its small number of patients. Confounding factors, such as iodine consumption, were difficult to control and may have influenced the results. Furthermore, the use of a neuropsychological battery including tests other than the WCST may be helpful in measuring other potentially relevant cognitive functions.

Our findings displayed that executive dysfunctions as measured with WCST were no more common in the euthymic bipolar patients than they were among the healthy controls. Moreover, thyroid volume in patients with bipolar disorder was not related with WCST performance. Obviously, more researches with greater number of patients are required to draw a precise conclusion.

\section{References}

1. McKnight RF, Adida M, Budge K, Stockton S, Goodwin GM, et al.(2012) Lithium toxicity profile: a systematic review and meta-analysis. See comment in PubMed Commons below Lancet 379: 721-728.

2. Davis JD, Tremont G (2007) Neuropsychiatric aspects of hypothyroidism and treatment reversibility. Minerva Endocrinol 32: 49-65.

3. van Boxtel MP, Menheere PP, Bekers O, Hogervorst E, Jolles J (2004) Thyroid function, depressed mood, and cognitive performance in older individuals: the Maastricht Aging Study. Psychoneuroendocrinology 29: 891-898.

4. Abend WK, Tyler HR (1995) Thyroid disease and trhe nervous system. Ed.Aminoff MJ, Neurology and General Medicine, Livingstone second edition, New York 333-47.

5. Canaris GJ, Manowitz NR, Mayor G, Ridgway EC (2000) The Colorado thyroid disease prevalence study. S Arch Intern Med 160: 526-534.

6. Jorde R, Waterloo K, Storhaug H, Nyrnes A, Sundsfjord J, et al. (2006) Neuropsychological function and symptoms in subjects with subclinical hypothyroidism and the effect of thyroxine treatment. J Clin Endocrinol Metab 91: 145-153.

7. Sadock BJ, Sadock VA (2000) Comprehensive Textbook of Psychiatry. Volume 2, 7th Edition, Philadelphia, Lippincott Williams Wilkins.

8. Deodhar SD, Singh B, Pathak CM, Sharan P, Kulhara P (1999) Thyroid functions in lithium-treated psychiatric patients: a cross-sectional study. Biol Trace Elem Res 67: 151-163.

9. Perrild H, Hegedüs L, Baastrup PC, Kayser L, Kastberg S (1990) Thyroid function and ultrasonically determined thyroid size in patients receiving long-term lithium treatment. Am J Psychiatry 147: 1518-1521.

10. Bocchetta A, Bernardi F, Pedditzi M, Loviselli A, Velluzzi F, et al. (1991) Thyroid abnormalities during lithium treatment. Acta Psychiatr Scand 83: 193-198.

11. Lee S, Chow CC, Wing YK, Shek CC (1992) Thyroid abnormalities during chronic lithium treatment in Hong Kong Chinese: a controlled study. J Affect Disord 26: 173-178.
12. Bocchetta A, Cherchi A, Loviselli A, Mossa P, Velluzzi F, et al. (1996) Sixyear follow-up of thyroid function during lithium treatment. Acta Psychiatr Scand 94: 45-48.

13. Loviselli A, Bocchetta A, Mossa P, Velluzzi F, Bernardi F, et al. (1997) Value of thyroid echography in the long-term follow-up of lithiumtreated patients. Neuropsychobiology $36: 37-41$.

14. Lazarus JH (1998) The effects of lithium therapy on thyroid and thyrotropin-releasing hormone. See comment in PubMed Commons below Thyroid 8: 909-913.

15. Bocchetta A, Loviselli A (2006) Lithium treatment and thyroid abnormalities. Clin Pract Epidemiol Ment Health 2: 23.

16. Bartalena L, Bogazzi F, Martino E (1999) Is thyroxine during lithium therapy necessary? J Endocrinol Invest 22: 220-222.

17. Martino E, Placidi GF, Sardano G, Mariotti S, Fornaro P, et al. (1982) High incidence of goiter in patients treated with lithium carbonate. Ann Endocrinol (Paris) 43: 269-276.

18. Schiemann U, Hengst K (2002) Thyroid echogenicity in manicdepressive patients receiving lithium therapy. J Affect Disord 70: 85-90.

19. Bernstein JG (1995) Drug Therapy in Psychiatry. 3rd Ed., Massachusetts: Aimes Mirror Company.

20. Tuglular I (1991) PsikiyatrideIlaçKullanimi Baski, Izmir, Ege Üniversitesi Basimevi 257-298.

21. Bauer M1, Blumentritt H, Finke R, Schlattmann P, Adli M, et al. (2007) Using ultrasonography to determine thyroid size and prevalence of goiter in lithium-treated patients with affective disorders. J Affect Disord 104: 45-51.

22. Ozpoyraz N, Tamam L, Kulan E (2002) Thyroid abnormalities in lithium-treated patients. Adv Ther 19: 176-184.

23. Ozsoy S, Mavili E, Aydin M, Turan T, Esel E (2010) Ultrasonically determined thyroid volume and thyroid functions in lithium-naïve and lithium-treated patients with bipolar disorder: a cross-sectional and longitudinal study. Hum Psychopharmacol 25: 174-178.

24. Schmittmann VD, Visser I, Raijmakers ME (2006) Multiple learning modes in the development of performance on a rule-based categorylearning task. Neuropsychologia 44: 2079-2091.

25. Karakas S, Irak M, Ersezgin ÖU (1998) Wisconsin KartEslemeTesti (WCST) ve StroopTesti TBAG form upuanlarinintestiçivetestlerarasiiliskileri. X. Ulusal Psikoloji Kongresiözetkitabi 44.

26. Heaton RK (1981) Wisconsin Card Sorting Test Manual. Odessa-Florida, USA, Psychological Assessment Resourices Inc.

27. Akdemir A, Örsel S, Dag I, Turkcapar H, Iscan N, et al. (1996) Hamilton Depresyon Derecelendirme Ölçegi' ningeçerliligi, güveni lirligiveklini ktekullanimi. Psikiyatri Psikoloji Psikofarmakoloji Dergisi 4: 251-9

28. KaradaÄŸ F, Oral T, YalÃ§in FA, Erten E (2002) [Reliability and validity of Turkish translation of Young Mania Rating Scale]. Turk Psikiyatri Derg 13: 107-114.

29. First MB, Spitzer RL, Gibbon M, Williams JBW (1997) Structured Clinical Interview for DSM-IV Axis I Disorders -Clinical Version (SCIDCV). Washington, DC: American Psychiatric Press.

30. Çorapçioglu A, Aydemir Ö, Yildiz M, Esen A, Köroglu E (1999) Structured Clinical Interview for DSM-IV Axis I Disorders -Clinical Version (SCID-CV) in Turkish version: Study of reliability. IlaçveTedaviDergisi 12: 233-236.

31. Spitzer RL, Williams JBW, Gibbon M, First M (1990) Structured Clinical Interview for DSM-III-R, Non-Patient Edition. Washington DC, American Psychiatric Press.

32. Sorias S, Saygili R, Elbi H (1990) Turkish version of Structured Clinical Interview for DSM-III-R, Non-Patient Edition , Bornova, Ege Üniversitesi Basimevi (in Turkish).

33. Barceló F, Knight RT (2002) Both random and perseverative errors underlie WCST deficits in prefrontal patients. Neuropsychologia 40: 349-356.

34. Howieson DB, Lezak MD (2002) The Neuropsychological Evaluation. Textbook of Neuropsychiatry and Clinical Neurosciences, 
Citation: Fistikci N, Canturk G, Saatcioglu O, Erten E, Keyvan A, et al. (2014) Executive Functions and Thyroid Volumes in Bipolar Patients on Lithium Treatment. J Psychiatry 17: 1000145. doi:10.4172/2378-5756.1000145

Page 6 of 6

Baski.Yudofsky SC, Hales RE (Ed), Washington. American Psychiatric

Publishing Inc 217-244.
35. Barcelo F, Sanz M, Molina V ve Rubai FJ (1997) The Wisconsin Card Sorting Test and the assessment of frontal function: A validation study with event related potentials. Neuropsychologia 35: 399-408. 